\title{
O USO DE FERRAMENTAS DE GESTÃO DE DADOS ON-LINE EM DISPOSITIVOS MÓVEIS: UMA PERSPECTIVA INTERATIVA NA GESTÃO DA AVALIAÇÃO DA APRENDIZAGEM ESCOLAR
}

\author{
EL USO DE HERRAMIENTAS DE GESTIÓN DE DATOS ON-LINE EN \\ DISPOSITIVOS MÓVIL: UNA PERSPECTIVA INTERACTIVA EN LA GESTIÓN DE \\ LA EVALUACIÓN DEL APRENDIZAJE ESCOLAR
}

\begin{abstract}
THE USE OF DATA MANAGEMENT TOOLS ON-LINE IN MOBILE DEVICES: AN INTERACTIVE PERSPECTIVE IN THE MANAGEMENT OF SCHOOL LEARNING EVALUATION
\end{abstract}

\author{
Alan César Belo ANGELUCI ${ }^{1}$ \\ Claudia Valeria OKAYAMA ${ }^{2}$
}

RESUMO: O objetivo deste trabalho foi investigar como os dispositivos móveis, por meio de aplicativo de gestão de dados on-line, podem beneficiar o professor na avaliação da aprendizagem de seus alunos. Para tanto, optou-se pelo método de pesquisa-ação, aplicado em uma escola privada do município de São Paulo, com professores e alunos do $8^{\circ}$ ano do Ensino Fundamental. Os dados foram coletados por meio de entrevistas semiestruturadas, grupo focal e observação dos alunos em situações avaliativas com dispositivos móveis. Verifica-se como resultado que o uso do aplicativo de gestão de dados contribui para o monitoramento e regulação da aprendizagem do aluno, porém, requer a instrumentalização e engajamento do professor, além de ambiente escolar com acesso à rede de Internet sem fio e a disponibilidade de dispositivos móveis, seja do aluno ou da instituição.

PALAVRAS-CHAVE: Dispositivos móveis. Avaliação formativa. Aprendizagem on-line. Literacia digital. Cultura digital. Aplicativos.

RESUMEN: El objetivo de este trabajo es investigar cómo los dispositivos móviles, a través de la aplicación de gestión de datos en línea, pueden beneficiar al profesor en la evaluación del aprendizaje de sus alumnos. Para ello, se optó por el método de investigación-acción, aplicado en una escuela privada del municipio de São Paulo, con profesores y alumnos del $8^{\circ}$ año de la Enseñanza Fundamental. Los datos fueron recolectados por medio de entrevistas semiestructuradas, grupo focal y observación de los alumnos en situaciones evaluativas con dispositivos móviles. Se verifican como resultados que el uso de la aplicación de gestión de datos contribuye al monitoreo y regulación del aprendizaje del alumno, sin embargo, requiere la instrumentalización y el compromiso del profesor, además de ambiente escolar con acceso

\footnotetext{
${ }^{1}$ Universidade Municipal de São Caetano do Sul (USCS), São Caetano do Sul - SP - Brasil. Professor Doutor do Programa de Pós-graduação em Educação da Universidade Municipal de São Caetano do Sul. ORCID: <http://orcid.org/0000-0002-4093-0590>. E-mail: aangeluci@gmail.com.

${ }^{2}$ Universidade Municipal de São Caetano do Sul (USCS), São Caetano do Sul - SP - Brasil. Mestre em Educação pelo Programa de Pós-graduação em Educação da Universidade Municipal de São Caetano do Sul. ORCID: <https://orcid.org/0000-0003-3336-1307>. E-mail: clauokay@gmail.com.
} 
a la red de Internet inalámbrica y la disponibilidad de dispositivos móviles, ya sea del alumno o de la institución.

PALABRAS CLAVE: Dispositivos móviles. Evaluación formativa. Aprendizaje en línea. Alfabetización digital. Cultura digital. Aplicaciones.

ABSTRACT: The objective of this work is to investigate how mobile devices, through an online data management application, can benefit the teacher in the evaluation of their students' learning. To do so, we opted for the action research method, applied in a private school in the city of São Paulo, with teachers and students of the 8th year of elementary school. The data were collected through semi-structured interviews, focus group and observation of students in evaluative situations with mobile devices. The results show that the use of the data management application contributes to the monitoring and regulation of student learning, however, it requires the instrumentalization and engagement of the teacher, as well as the school environment with access to wireless Internet and availability of mobile devices, either the student or the institution.

KEYWORDS: Mobile devices. Formative evaluation. Online learning. Digital Literacy. Digital culture. Applications

\section{Introdução}

As pesquisas e reflexões apontam o descompasso do novo papel do professor, afirmando frequentemente que as formas atuais de qualificações dos docentes não têm sido adequadas ou suficientes para que possam enfrentar a complexidade dos problemas educacionais da contemporaneidade, e estão estreitamente ligadas à sua formação, à realidade da educação e da escola. A formação de professores nos cursos de graduação presencial, em sua maioria, é realizada predominantemente por meio de recursos didáticos mecânicos e analógicos e, em menor escala, com a utilização dos recursos das redes de informática. A formação continuada convencional também percorre o mesmo caminho, embora esteja passando por um processo de inovação com os cursos de educação a distância (PARENTE; VALLE; MATTOS, 2015).

O paradoxal é que a introdução das tecnologias na Educação é função dos educadores, que, por sua vez, recebem alunos com razoável domínio tecnológico, familiarizados com laptops, tablets e smartphones, navegando na Internet, ainda que muitas vezes de maneira escassa, isolada e dispersa, vulneráveis ao que é colocado à sua disposição nas redes sociais e nos sites de busca, o que amplia a responsabilidade da escola e dos professores (FELDMANN, 2009). No Ensino Básico, especificamente nos anos finais do Ensino Fundamental, contemplase a necessidade do professor em valorar a tecnologia digital não apenas como recurso, mas como bem cultural socializador de conhecimento. Ensinar a transformar informação em saberes 
se faz necessário num tempo em que a velocidade e a quantidade de informações assolam nossos jovens todos os dias.

Rossing (2012) aponta que o uso crescente dos dispositivos móveis é tendência mais atual, possibilitando aos educadores conhecer os méritos e limitações dos novos usos das tecnologias digitais na sala de aula, interagindo com uma gama maior de informações em um processo interativo e colaborativo. Imersos numa cultura digital em que os dispositivos móveis estão cada vez mais presentes na sociedade, possibilitando múltiplos usos, o maior enfrentamento dos professores não são as transformações tecnológicas ou a velocidade das informações, mas a construção de uma nova prática pedagógica, dialógica, dinâmica e desafiadora, neste novo cenário que se apresenta. Diante deste cenário, delimitou-se o problema que norteia este estudo: como os dispositivos móveis, por meio de aplicativos de gestão de dados on-line, podem beneficiar o professor na avaliação da aprendizagem de seus alunos? Assim, esta pesquisa teve como objetivo principal analisar se o aplicativo do Google - o Formulário Google - pode apresentar interface com o conteúdo explorado por diversas áreas de conhecimento do Ensino Fundamental nos anos finais, com critérios predefinidos para o uso dentro e fora de sala de aula, em situações avaliativas.

\section{Aprendizagem móvel e o papel do professor}

O estudante atual vivencia uma era digital em que se dá a relação entre ensino e aprendizagem, numa cultura escolar que contempla os dispositivos digitais móveis na construção dos saberes, possibilitando a Aprendizagem Móvel. Segundo a $\operatorname{UNESCO}^{3}$ (2014, p. 8), entende-se por aprendizagem móvel o uso de tecnologias móveis, isoladamente ou em combinação com outras Tecnologias de Informação e Comunicação (TIC), a fim de permitir a aprendizagem a qualquer hora e em qualquer lugar. O M-Learning, ou Aprendizagem Móvel, comporta recursos inovadores tecnológicos. Em oposição à sala de aula formal, novas metodologias possibilitam potencializar a relação entre ensino e aprendizagem, favorecendo ao aluno a construção do conhecimento por meio da colaboração, interação e autoconhecimento, características da proposta das metodologias ativas, entre elas o ensino híbrido, sala de aula invertida e aprendizagem colaborativa.

Porém, vale ressaltar que investir em tecnologias, instrumentos e novas mídias não substituirá um bom professor: apenas esse tem o poder e a capacidade de motivar, incentivar e

\footnotetext{
${ }^{3}$ Organização das Nações Unidas para a Educação, a Ciência e a Cultura.
} 
levar o aluno ao aprendizado significativo. Nóvoa (2007) ressalta que não há como substituir o contato humano, o diálogo e o desejo de aprender que os bons professores sabem favorecer.

Os dispositivos móveis, por si só, podem não promover inovações na educação. $\mathrm{O}$ educador que possui engajamento, desejo pelo conhecimento e está aberto ao novo, pode assumir a importante postura de aprendiz em sua profissão, refletindo e transformando constantemente sua prática docente e sua profissionalidade; de acordo com Tardif e Lessard (2005, p. 38), os professores são atores que “[...] dão sentido e significado aos seus atos, e vivenciam sua função como uma experiência pessoal, construindo conhecimentos e uma cultura própria da profissão". Neste contexto se insere a avaliação, alvo de muitas discussões inerentes à profissionalidade docente.

\section{Avaliação on-line}

Na perspectiva deste trabalho, avaliar é poder rever direções, projetar novos rumos, ou mesmo manter o caminho percorrido pelo êxito dos seus resultados. É também um indicador importante para que o professor possa avaliar sua prática, apontando acertos, para continuar sua trajetória com os alunos ou refletir sobre erros para que possa planejar novos rumos de modo a atender as necessidades de aprendizagens individuais e do grupo. Os recursos tecnológicos móveis, aliados às metodologias ativas, podem corroborar com uma avaliação formativa, desde que o professor tenha domínio tanto dos recursos tecnológicos quanto do processo da avaliação reguladora da aprendizagem do aluno. A avaliação on-line corrobora com uma prática dialógica a serviço da aprendizagem do aluno. $\mathrm{O}$ ambiente colaborativo, a possibilidade de feedbacks rápidos, o protagonismo do aluno e situações de aprendizagem desafiadoras podem ser aplicadas por meio de diversas ferramentas disponíveis.

Para a implementação da avaliação on-line, por meio de dispositivos móveis, há de se considerar vantagens e desvantagens que o professor poderá enfrentar, segundo a Figura 1.

Figura 1: Vantagens e desvantagens do uso dos dispositivos móveis na avaliação 


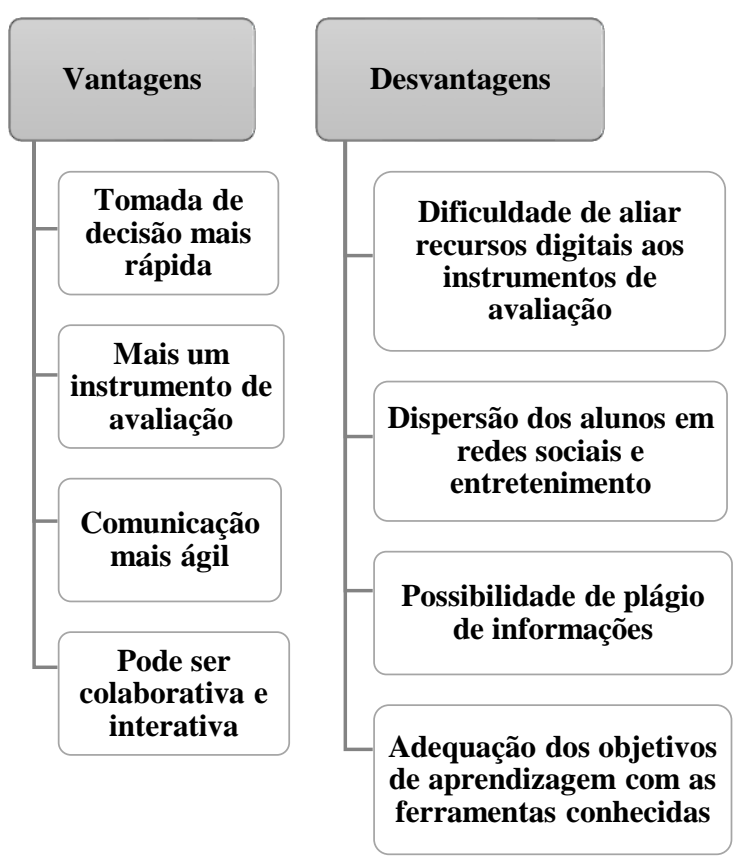

Fonte: Elaboração própria

A integração das tecnologias em vários contextos educativos demonstra que os processos de ensino e aprendizagem com frequência extrapolam os espaços de ensino presenciais ou on-line. Balula (2014) aponta que a avaliação da aprendizagem não pode servir apenas para quantificar resultados, mas influir na forma como interagem os conceitos de aprendizagem digital e avaliação on-line, permitindo, acima de tudo, uma aprendizagem significativa.

De Andrade e Pinto (2013) tratam o Google Docs e suas aplicações como recursos valorosos na realização de avaliações, permitindo a elaboração de diferentes tipos de questões (abertas, relacionais, múltipla escolha), proporcionando respostas aos alunos via e-mail, geração de gráficos, sumarização de dados e ambiente possível de verificação do rendimento da turma do aluno, individualmente e processual, de modo ágil e otimizado. $\mathrm{O}$ aplicativo possibilita coletar trabalhos, aplicar avaliações, inserir vídeos ou imagens às questões, correção automática das perguntas, formar banco de dados para avaliação contínua e receber feedback automático. Em função da exploração dos benefícios do aplicativo Formulário Google para avaliação da aprendizagem é que se propõe essa pesquisa.

\section{Procedimentos metodológicos}

A pesquisa teve como objetivo investigar se o uso do Formulário Google na verificação da avaliação por meio de dispositivos móveis corroborava com um processo facilitador para o 
professor na correção, no monitoramento do desempenho e na comunicação dos resultados para os alunos. Para tanto, selecionou-se, por conveniência, uma escola particular da cidade de São Paulo, que aceitou a realização desta pesquisa. A escola, de porte médio, tem cerca de 450 alunos e atua nos segmentos da Educação Infantil e do Ensino Fundamental. Delimitou-se enquanto público os alunos e professores do $8^{\circ}$ ano do Ensino Fundamental, que, em sua maioria, pela faixa etária, faz uso de dispositivos móveis, como também a possibilidade de acompanhamento dos alunos, que encerram o ciclo na instituição no $9^{\circ}$ ano. Em discussão preliminar sobre a pesquisa com os professores, seis, no total de nove deles, aceitaram fazer parte do estudo, os quais lecionam nas áreas de Educação Física, Matemática, Ciências Naturais, Língua Inglesa, História e Artes Visuais. Os outros professores declinaram o convite alegando falta de tempo para dedicação à pesquisa. A metodologia definida para este trabalho é a pesquisa-ação, seguindo etapas de coleta de dados por meio de instrumentos de pesquisa, tais como: questionário semiestruturado com gestores e professores com a finalidade de constatar a aceitação tecnológica dos mesmos, grupo focal com professores e alunos no início da pesquisa para compreender a concepção de ensino, e de avaliação e término com objetivo de avaliar a implementação do plano de ação (elaboração e aplicação de avaliações on-line por meio de dispositivos móveis), além de observação em sala de aula durante realização da avaliação no Formulário Google.

\section{Resultados e discussão teórica da pesquisa}

Por meio dos instrumentos de pesquisa, como questionário semiestruturado com os gestores e professores e grupo focal com os alunos, concluímos que o uso de dispositivos móveis não faz parte da cultura escolar, mas há uma preocupação com a aprendizagem móvel que faz parte do planejamento da direção. Há equipamentos (tablets), porém pouco utilizados pelos alunos. A falta do livre acesso à rede Wi-Fi limita o uso em sala de aula por alunos e professores, e a formação docente para o uso das tecnologias é apontada como um dos fatores que causa insegurança ao professor para diversificar sua prática por meio da mídia móvel, contemplando as reflexões da UNESCO (2014, p. 51): "Uma das barreiras mais resistentes ao desenvolvimento da aprendizagem móvel é a falta de educadores treinados que possam efetivamente incorporar o uso de tecnologias móveis na sala de aula".

Em sua maioria, os alunos são portadores de dispositivos móveis e os utilizam para estudos fora do ambiente escolar, por iniciativa e com os recursos que aprenderam sem auxílio docente, o que leva a refletir, de acordo com Feldmann (2009), que a introdução das tecnologias 
na educação é função dos educadores, que recebem alunos muitas vezes vulneráveis ao que é colocado à sua disposição nas redes sociais e nos sites de busca, o que amplia a responsabilidade da escola.

No que tange ao processo avaliativo, nos dados coletados por meio dos grupos focais com professores e alunos, percebemos a preocupação de que a avaliação seja um processo contínuo, situando o aluno no centro da aprendizagem. A proposta de avaliar por meio de objetivos de aprendizagem, isto é, com metas e critérios definidos, favorece a compreensão das conquistas e dificuldades dos alunos, principalmente porque são utilizados diversos recursos nesse processo (provas, trabalhos, pesquisas, entre outros), o que corrobora com Gatti (2003), no sentido de que a avaliação deve ser continuada, variada, com instrumentos e elementos diversificados, criativos e utilizada no próprio processo de ensino. É possível inferir que o processo avaliativo faça parte do planejamento do professor, porém, não há dados suficientes para inferir que o aluno desenvolve a regulação da sua aprendizagem, controlando fatores ambientais, cognitivos e afetivos, percebendo suas conquistas e mobilizando-se para resolver suas dificuldades, conforme sugerem Black e William (2009). Há um contrassenso no que se refere ao tempo de entrega da correção individual ao aluno. Professores calculam uma semana em média para comunicação dos resultados, mas os alunos apontam um tempo maior para esse retorno, demonstrando que nas situações avaliativas nem sempre há um feedback rápido aos alunos.

Foi realizada uma breve oficina para a apropriação do aplicativo Formulário Google pelos pesquisados, com objetivo de conhecê-lo ou refinar os conhecimentos do recurso. Elaborou-se um contrato de ação junto aos pesquisados com a finalidade de estabelecer as ações pretendidas, as funções de cada um, o tempo de dedicação, a assimilação das tecnologias, a troca de experiência, o caminho metodológico e o acompanhamento do processo, de acordo com Abdalla (2005). Junto aos professores, elaboraram-se as atividades avaliativas, de acordo com objetivos e conteúdos especificados por eles, e a aplicação, com os alunos, por meio de dispositivos móveis.

A partir dos dados coletados, observa-se que os dispositivos móveis pouco fazem parte da cultura escolar, apresentando-se uma política clara para utilização, isto é, em momentos de entretenimento dos alunos, ou com os equipamentos fornecidos pela escola (tablets) com fins educativos. É possível analisar o plano de ação sob alguns aspectos: o professor, o aluno, a infraestrutura para uso da mídia móvel e o próprio aplicativo de gestão de dados, o Formulário Google. Os professores, aparentemente, em sua maioria, demonstraram certa resistência para elaborar as avaliações no Formulário Google, mas não em aplicá-las. O aplicativo é simples e 
intuitivo, mas é necessário planejar a atividade levando em conta suas potencialidades e suas fragilidades. Para tanto, conhecê-la é o primeiro passo, e o professor, além da elaboração da atividade avaliativa, necessita explorá-la adequando-a aos seus objetivos. A maioria dos pesquisados não explorou o aplicativo para planejar a atividade, assim, a função de criar as atividades no formulário e repassar ao professor para sua validação ficou a cargo do pesquisador.

Outro ponto fundamental é o uso das tecnologias durante as aulas. A avaliação é um momento de verificação em que, supostamente, o professor planeja que não haja imprevistos que prejudiquem o aluno. À medida que as aulas não contemplam metodologias com o uso de dispositivos móveis, o professor não está instrumentalizado para lidar com imprevistos e resolver problemas, podendo gerar insegurança quanto à sua competência com o que ainda é desconhecido, ratificando a hipótese de que a falta da tecnologia como recurso didático nas aulas pode ocasionar dificuldades quanto ao equipamento ou o aplicativo utilizado. Assim, a formação do professor para o conhecimento das metodologias e recursos da aprendizagem móvel constatou-se necessária durante a pesquisa.

A partir da análise dos dados é possível sintetizar as recomendações positivas, negativas e aquelas que merecem atenção no uso do Formulário Google para situações avaliativas, de acordo com a Figura 2.

Figura 2: Potencialidades e fragilidades encontradas na pesquisa durante a aplicação do Formulário Google em situações avaliativas por meio de dispositivos móveis

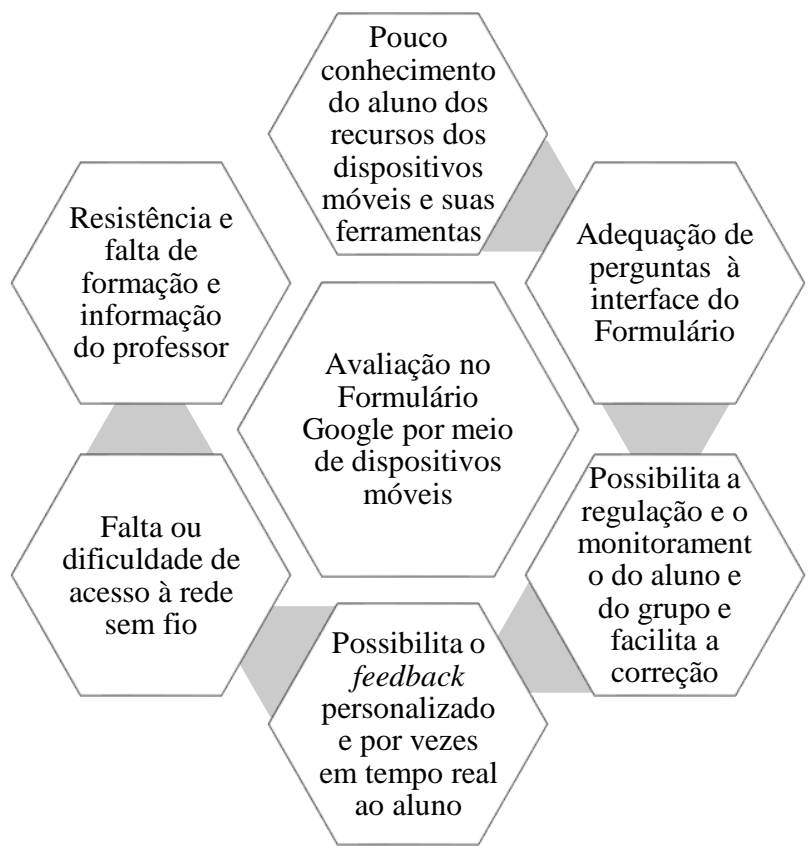

Fonte: Elaboração própria 
O Formulário de gestão de dados on-line mostra-se eficiente à medida que possibilita a verificação das respostas dos alunos individualmente e no coletivo, por meio de resumos que indicam o número de acertos e erros, traduzindo também em gráficos e planilhas o desempenho do aluno e do grupo em cada questão, o que oportuniza ao professor definir os rumos do ensino para aprendizagem personalizada ou do grupo. Questões de múltipla escolha podem ser corrigidas automaticamente, gerando pontuação, facilitando o trabalho de correção do professor. $\mathrm{O}$ feedback ao aluno é um diferencial do formulário. $\mathrm{O}$ aluno pode receber uma cópia das suas respostas, receber as respostas corrigidas automaticamente com pontuação em caso de múltipla escolha, além da comunicação do professor por escrito indicando conquistas, apontando dificuldades e até mesmo percursos a serem seguidos pelo aluno. Por outro lado, o Formulário Google em dispositivos móveis apresenta fragilidade em ambiente sem conexão à Internet: é um aplicativo on-line, depende de conexão à Internet. Outra fragilidade é a falta de engajamento e formação dos professores para apropriar-se de recursos e ferramentas contempladas pelos dispositivos móveis. Não basta o professor conhecer o Formulário, é necessário explorar suas potencialidades e fragilidades, solucionando problemas colaborativamente, compartilhando a responsabilidade da aprendizagem com o aluno.

Faz-se necessária a atenção às questões formuladas que necessitam adequação ao Formulário, assim, o professor precisa conhecer e explorar as potencialidades e as fragilidades do aplicativo. Outro ponto relevante é o conhecimento que o aluno tem do equipamento, do Formulário e de outras aplicações necessárias para utilizar o Formulário Google, como o email, que, no caso, os alunos pesquisados encontraram dificuldades: alguns não tinham, outros tinham e não utilizavam e alguns ainda não sabiam manuseá-lo.

Diante dos aspectos observados na pesquisa é importante salientar que a avaliação formativa não é um momento único, e sim um processo intrínseco ao ensino e aprendizado. É uma concepção, uma postura do professor diante de sua prática na regulação e monitoramento do aprendizado do aluno. As situações avaliativas que permearam a pesquisa distam dessa possibilidade, apresentando-se em situações avaliativas pontuais, com instrumentos selecionados já concebidos no planejamento do professor para sua participação no projeto. Porém, pequenas ações deflagram concepções de aprendizagem e, mesmo não acompanhando o processo avaliativo em sua totalidade, pois não era o objetivo desta pesquisa, é possível inferir que alguns dos educadores participantes da pesquisa mobilizam-se para uma avaliação em que o aluno seja protagonista e adquira a corresponsabilidade da aprendizagem, à medida que fornecem feedbacks, discutem o aprendizado e são voluntários de uma pesquisa para implementar novas formas de avaliação. 
É fato que os professores e alunos pesquisados pouco utilizam os dispositivos móveis para fins educacionais. Assim, o processo avaliativo on-line no Formulário Google por meio de dispositivos móveis de certa forma é uma novidade, exigindo que fossem aprendendo alguns de seus recursos ao utilizá-lo. A aprendizagem móvel como prática docente e discente talvez corroborasse com um processo avaliativo mais eficaz, pois os usuários teriam familiaridade com os recursos, ferramentas e equipamentos. Porém, é necessário começar, e os professores envolvidos vivenciaram a experiência com a mídia móvel, conhecendo alguns de seus obstáculos e benefícios.

Durante o período de avaliação por meio do Formulário Google, constatou-se que os alunos participantes apresentaram dificuldades com o equipamento e os recursos tecnológicos. São nativos digitais, segundo Prensky (2001), mas há de se considerar o uso que os estudantes fazem dos dispositivos móveis. Uma das premissas desta pesquisa é que a facilidade e o contato constante com a mídia móvel pelo aluno podem tornar a aprendizagem móvel praticamente intrínseca ao seu universo, que é permeado de recursos virtuais e digitais. É provável que o aluno esteja imerso na cultura digital e acessando dispositivos móveis, tendo a possibilidade de obter as informações do mundo na "palma da mão", porém, é necessário saber o que fazer com elas e como fazer. A pesquisa apresentou um cenário em que os alunos, em sua maior parte portadores de dispositivos móveis, pouco conheciam os recursos apresentados. Armazenamento na nuvem, código QR e o próprio Formulário Google presume-se que ficaram conhecidos durante as etapas da pesquisa pela maior parte dos alunos. Confrontando a premissa de que os alunos teriam competência para utilizar os dispositivos móveis e ferramentas propostas, apresentando maior apropriação dos recursos, infere-se que o conhecimento demonstrado é o que aprenderam e utilizam para fins pessoais e pouco para fins educacionais, já que a escola não contempla os dispositivos móveis no ensino e aprendizado.

Diante dessa constatação, é possível compreender porque, durante o grupo focal, os alunos deram preferência às avaliações tradicionais com caneta e papel, território conhecido e explorado para um momento de avaliação, às on-line. Por outro lado, a observação nos momentos da avaliação no Formulário Google aponta a possibilidade de situações em que os alunos tiveram que apresentar autonomia, desenvolver ou acionar habilidades para a resolução de problemas, não apresentando o mesmo resultado na proposta de sala de aula invertida, em que apenas um pouco mais da metade do grupo concluiu a atividade, tendo como principal justificativa a dificuldade do aluno com o e-mail. Nas propostas de atividades em grupo com os dispositivos móveis, presume-se que os mesmos favoreceram a aprendizagem colaborativa 
à medida que construíram juntos a proposta, sem mediação do professor. Os alunos apontaram a necessidade de mais situações que possam ser avaliadas em pares.

Para que o aluno se aproprie das possibilidades que o dispositivo móvel oferece para fins educacionais, a escola pode desempenhar o papel de mediadora deste processo, possibilitando-lhe o desenvolvimento da autonomia para autoformação. Neste contexto, é possível vislumbrar alguns caminhos. A escola tem o papel de proporcionar aos docentes a formação necessária para atuar com os alunos por meio das novas tecnologias, empregando metodologias ativas, caso contrário, a inovação espelha somente equipamentos de última geração, mas a aula permanece a mesma, alterando apenas o recurso utilizado. Os educadores, por sua vez, necessitam assumir o papel de pesquisador e buscar formação para inovar a prática em sala de aula. A indagação e a pesquisa fazem parte da prática docente e na sua formação contínua o professor precisa assumir-se como pesquisador, considera Freire (2002).

Outro ponto a ser destacado é a infraestrutura tecnológica da instituição escolar. A aprendizagem móvel na escola depende da conexão à Internet e de equipamentos, seja dos alunos ou da instituição. A política de acesso à rede sem fio na escola pesquisada pautava-se na utilização apenas nos próprios equipamentos, limitando o uso de alunos e professores. Durante a pesquisa, o acesso à Internet esteve limitado aos tablets, condicionado ao uso de senha. A rede sem fio era instável na maioria dos locais e alguns problemas de conexão foram vivenciados pelos alunos durante as avaliações. Vale ressaltar que a infraestrutura oferecida pela instituição escolar é imprescindível na percepção dos professores pesquisados, e a falta de acesso à rede Wi-Fi foi unânime entre eles como impeditivo para a aplicação de novas propostas com o uso de dispositivos móveis, seja na sala de aula com alunos ou para a pesquisa e elaboração de atividades.

Por fim, o Formulário Google e sua funcionalidade para avaliação da aprendizagem. Os professores apontam que há maior adequação para atividades de múltipla escolha, salientam a facilidade da correção e comunicação imediata dos resultados e ponderam a utilização de questões dissertativas, principalmente com gabaritos, pois o aluno necessita responder de forma exata ao gabarito, caso contrário a questão é considerada errada.

Comparando as situações de avaliações com e sem dispositivos móveis, o tempo programado para a atividade, a disposição das carteiras no espaço da sala (exceto avaliação em grupo) e as instruções do professor foram comuns. O aplicativo de gestão de dados ou o recurso não diferencia a atividade, pois esse é papel exclusivo do professor, e mesmo diante do recurso tecnológico inovador sua prática tem que ser condizente com o objetivo proposto. 
A correção favorecida pelo Formulário Google, enviada ao aluno logo após o término da avaliação, favoreceu a autocorreção e o monitoramento da aprendizagem, possibilitando a troca entre os pares, inclusive discutindo as questões. Os alunos mencionam a dificuldade em digitar nos tablets e a preferência pelo uso da própria mídia móvel para a realização das atividades, por ser mais rápido utilizar apenas dois dedos para teclar. $\mathrm{O}$ aplicativo de gestão de dados on-line utilizado como recurso para atividades avaliativas nesta pesquisa teve como objetivo verificar de quais formas pode-se auxiliar o professor na correção, monitoramento do desempenho e na comunicação mais eficiente com os alunos, e investigar o uso do Formulário Google como aplicativo de gestão de dados para aplicação de avaliação junto a jovens dos anos finais do Ensino Fundamental.

Uma das principais características do Formulário Google é o acesso livre e gratuito, assim, o aplicativo estava disponível para todos os participantes da pesquisa sem a necessidade de instalação ou compra. Por outro lado, para utilizá-lo, a conexão à rede de Internet se faz necessária, operando apenas no modo on-line. A elaboração das avaliações no Formulário conta com a possibilidade de personalização, desde a escolha da cor, tema, foto, tornando-as atraentes e adequando-as aos assuntos em questão. A escolha do título facilitava o armazenamento, podendo incluir uma descrição, realizada em algumas atividades. A escolha das questões no Formulário, de cada área de conhecimento participante, procurou adequar-se aos recursos disponíveis.

Questões de múltipla escolha não necessitaram de ajustes, sendo possível criar o número de alternativas desejadas, gabarito na chave de respostas e nas configurações, além de criar testes atribuindo pontuação. A correção nesta perspectiva é automática, facilitando o trabalho do professor. O Formulário Google apresenta um resumo das respostas por meio de gráficos, apontando o número de alternativas respondidas, as respostas erradas com frequência e a pontuação de cada aluno, assim o professor tem dados do grupo, regulando a aprendizagem em cada objetivo proposto, podendo rever, inclusive, conteúdos que precisam ser retomados ou que foram assimilados. Há a possibilidade de acessar as respostas do grupo por meio de uma planilha no Excel, gerada automaticamente. Respostas individuais são visualizadas, verificando a aprendizagem de cada um, podendo o professor adicionar um feedback ao aluno para cada questão, posteriormente enviado a ele por meio do e-mail que o aluno registrou no formulário.

Durante a pesquisa, algumas questões de uma das avaliações foram criadas para receber mais de uma resposta correta, por meio de pergunta múltipla escolha e lista suspensa, ocasionado em dificuldade aos alunos, que conseguiam marcar apenas uma alternativa. 
Posteriormente descobriu-se que para esse tipo de pergunta a caixa de seleção é a opção para marcar mais de uma resposta.

As questões discursivas, que exigem respostas com texto curto ou longo, são possíveis de inserir no Formulário. Respostas que não são padronizadas não são possíveis de corrigir automaticamente. Nestes casos, o professor obtém as respostas do grupo e individuais, realizando a correção manual e podendo, da mesma forma, enviar ao aluno o feedback, seja para autocorreção, ao criar o teste e uma resposta modelo para a chave de resposta, ou sem a criação de testes, enviando um feedback individual para o e-mail do aluno.

A gestão da aprendizagem e do ensino é favorecida à medida que facilita o trabalho do professor em obter as respostas em um único local, efetivando uma comunicação eficiente ao educando. Ao elaborar as avaliações, o Formulário permite a inserção de figuras que foram selecionadas pelo professor e enviadas ao formulário. Há várias opções para inseri-las: upload, banco de imagens, URL e até mesmo pesquisa on-line.

A opção dos professores foi o upload de imagens preexistentes. Vídeos podem fazer parte de perguntas, porém, são aceitos apenas do YouTube, no ícone "adicionar vídeo", sendo possível o professor manter um canal com uma coletânea de vídeos, ou, segundo o especialista em tecnologia educacional, fazer o upload do vídeo para o Drive do Google e inseri-lo na questão. Não há opção de inserção de áudio no Formulário, assim, não contemplou a avaliação que dispunha de uma pergunta de compreensão do idioma falado, necessitando editar o áudio em vídeo em programa específico e postá-lo no canal do YouTube para inseri-lo no Formulário Google.

Atualmente encontra-se a possibilidade de upload de arquivos do Google Drive, tanto para o desenvolvedor do Formulário quanto para o respondente do mesmo, porém, no caso das respostas, os alunos necessitariam fazer login no Google. Durante a pesquisa essa opção não se fazia presente. $\mathrm{O}$ aplicativo de gestão de dados para avaliação interativa da aprendizagem do aluno por meio de dispositivos móveis mostrou-se como mais um recurso no processo de avaliação em ambientes institucionais escolares que dispõe de acesso à rede Wi-Fi e contam com equipamentos próprios ou dos alunos.

É possível inferir que a concepção e a prática do professor, diante do processo de avaliação da aprendizagem, não se alteram com o uso da tecnologia em questão, mas colabora com aqueles que já possuem o intuito de regular e monitorar a aprendizagem do aluno, tornando-o protagonista da própria aprendizagem. Soluções criativas, inovação e disponibilidade para aprender são características do professor que trilha um caminho de ensino considerando o estudante da atualidade. 


\section{Considerações finais}

A presente pesquisa teve o objetivo de investigar como os aplicativos de gestão de dados on-line, por meio de dispositivos móveis, podem contribuir com um processo interativo na avaliação da aprendizagem. O Formulário Google, de acesso livre e gratuito, foi a opção para a realização da pesquisa. O caminho percorrido demonstra que os professores do cenário em questão não utilizam a mídia móvel no processo de ensino aprendizado, assim, distam da aprendizagem móvel. A experiência vivenciada pelos docentes nas atividades avaliativas com o Formulário Google demonstrou a viabilidade do mesmo em ser mais um instrumento avaliativo que corrobora com a prática da avaliação formativa à medida que permite regular, monitorar e comunicar a aprendizagem dos alunos por meio dos recursos disponíveis no aplicativo. Os professores citam que para atividades de múltipla escolha o Formulário se adequa com um perfil facilitador da correção e de feedback. Porém, verificou-se que a falta de formação e informação para o uso desta tecnologia impossibilitou-os de atestar os outros benefícios oferecidos.

A resistência em explorar e elaborar as atividades no Formulário demonstra a insegurança e a falta de domínio do uso de tecnologia para fins educacionais por parte dos educadores pesquisados. Por outro lado, adotar a mídia móvel em sala de aula depende da infraestrutura da escola, principalmente do acesso à rede Wi-Fi, a qual os professores e alunos apontam a necessidade de livre acesso a todos os envolvidos no processo educativo dentro da instituição escolar.

Os alunos apresentaram um comportamento próximo ao dos docentes, mostrando-se inseguros e resistentes ao utilizarem o aplicativo proposto. Mesmo em sua maioria portadores de dispositivos móveis, imersos na cultura digital, a linguagem tecnológica a que estão habituados perfaz as redes sociais, aplicativos e sites de entretenimento. Assim, recursos para uso educacional e construção de conhecimento são pouco explorados ou desconhecidos, ampliando a responsabilidade da escola e dos professores, como aponta Feldmann (2009). Assumir uma postura de agente transformador da realidade educacional não é tarefa fácil. É preciso engajamento, compromisso, formação continuada, reflexão, ação e reflexão sobre a própria prática.

\section{REFERÊNCIAS}


ABDALLA, M. F. B. A pesquisa-ação como instrumento de análise e avaliação da prática docente. Ensaio: Avaliação e Políticas Públicas em Educação, Rio de Janeiro, v. 13, n. 48, p. 383-400, jul./set., 2005.

BALULA, A. J. Avaliação digital como aprendizagem. Educação, Formação \&

Tecnologias, Portugal, v. 7, n. 1, p. 80-88, jan./jun., 2014.

BLACK, P; WILIAM, D. Developing the theory off formative assessment. Educational Assessment: Evaluation and Accountability. Formerly: Journal of Personnel Evaluation in Education, London, v. 21, n. 1, p. 1-40, 2009.

DE ANDRADE, A. M. R.; PINTO, G. P. Utilização do Google Docs como Ferramenta de Avaliação: Experiência do PIBID. Anais do Congresso Norte Nordeste de Pesquisa e Inovação, VIII CONNEPI, p. 1-7, 2013.

FELDMANN, M. G. Formação de professores e a escola na contemporaneidade. São Paulo: SENAC, 2009.

FREIRE, P. Pedagogia da autonomia. 25. ed. São Paulo: Editora Paz e Terra, 2002.

GATTI, B. O professor e a avaliação em sala de aula. Estudos em Avaliação Educacional, Fundação Carlos Chagas, São Paulo, n. 27, p. 97-114, jan./jun., 2003.

NÓVOA, A. Desafios do trabalho do professor no mundo contemporâneo. São Paulo: SINPRO, 2007.

PARENTE, C. M. D.; VALE, L. E. R.; MATTOS, M. J. V. M. A formação de professores e seus desafios frente às mudanças sociais, políticas e tecnológicas. Porto Alegre: Penso, 2015.

PRENSKY, M. Digital natives, digital immigrants part1. On the Horizon, v. 9, n. 5, p. 1-6, 2001. DOI: $10.1108 / 10748120110424816$.

ROSSING, J. et al. I Learning: The future of higher education? Student perceptions on learning with mobile tablets. Journal of the Scholar Ship of Teaching and Learning, v. 12, n. 2, p. 1-26, 2012.

TARDIF, M.; LESSARD, C. O trabalho docente: elementos para uma teoria da docência como profissão de interações humanas. Petrópolis: Vozes, 2005.

UNESCO. O Futuro da aprendizagem móvel: implicações para planejadores e gestores de políticas. Tradução pela Representação UNESCO Brasil. E-book. Brasília: UNESCO, 2014. 64 p. Incl. Bibl. ISBN: 978-85-7652-188-4. 


\section{Como referenciar este artigo}

ANGELUCI, Alan César Belo.; OKAYAMA, Claudia Valeria. O uso de ferramentas de gestão de dados on-line em dispositivos móveis: uma perspectiva interativa na gestão da avaliação da aprendizagem escolar. Revista Ibero-Americana de Estudos em Educação, Araraquara, v. 14, n. 2, p. 388-403, abr./jun. 2019. E-ISSN: 1982-5587. DOI: 10.21723/riaee.v14i2.11066

Submetido em: 21/02/2018

Revisões requeridas em: 10/04/2018

Aceito em: 10/07/2018 